\title{
Use of a Voxel Phantom as a Source and a Second Voxel Phantom as a Target to Calculate Effective Doses in Individuals Exposed to Patients Treated with ${ }^{131}$ I
}

\author{
Albérico B. de Carvalho, Jr. ${ }^{1}$, John Hunt ${ }^{2}$, Ademir X. Silva ${ }^{3}$, and Fermin Garcia ${ }^{1}$ \\ ${ }^{I}$ Departamento de Ciências Exatas e Tecnológicas, Universidade Estadual de Santa Cruz, Ilhéus, Brazil; ${ }^{2}$ Instituto \\ de Radioproteção e Dosimetria, Rio de Janeiro, Brazil; and ${ }^{3}$ Programa de Engenharia Nuclear/COPPE/Universidade Federal do Rio de \\ Janeiro, Rio de Janeiro, Brazil
}

\begin{abstract}
In this study, the Visual Monte Carlo radiation transport code and the female voxel phantom FAX were used to calculate organ and effective doses delivered by target-source irradiation geometries associated with radioiodine therapy treatments. Methods: Specific situations were considered: when a patient was accompanied during hospitalization, when a patient was accompanied on return to his or her residence, and when a patient received daily care at home. Results: This simulation study showed that, in the 3 situations considered, the total effective dose to an individual in normal contact with the patient was less than $0.85 \mathrm{mSv}$ for up to $11.1 \mathrm{GBq}(300 \mathrm{mCi})$ of administered activity. Conclusion: The results of this study suggest that for these patients receiving radioiodine therapy, radiation protection procedures after hospital discharge are unnecessary.
\end{abstract}

Key Words: radionuclide therapy; patient release; radiation safety; dosimetry; Monte Carlo method

J Nucl Med Technol 2009; 37:53-56

DOI: $10.2967 /$ jnmt.108.058172

\section{W}

hen ${ }^{131} \mathrm{I}$ is administered to a patient who has undergone a total thyroidectomy, the patient is typically hospitalized for at least $2 \mathrm{~d}$ after the administration to allow the dose rate to fall to acceptable levels. The patient is instructed to maintain a certain distance from family members for several days after hospital discharge (1). A total thyroidectomy removes almost all of the thyroid gland tissue. To achieve the total elimination of thyroid tissue, ${ }^{131}$ I activity is administered in the range of $3.7 \mathrm{GBq}(100 \mathrm{mCi})$ to $11.1 \mathrm{GBq}$ $(300 \mathrm{mCi})$ (2). This activity is concentrated in the remaining thyroid tissue; the high localized dose causes the death of the

Received Sep. 15, 2008; revision accepted Nov. 12, 2008.

For correspondence or reprints contact: Albérico B. de Carvalho, Jr., Departamento de Ciências Exatas e Tecnológicas, Universidade Estadual de Santa Cruz, Rodovia Ilhéus-Itabuna, Km 16, Ilhéus, Bahia 45650-000, Brazil. E-mail: ablohem@gmail.com

COPYRIGHT @ 2009 by the Society of Nuclear Medicine, Inc. remaining thyroid tissue cells. Current radiation protection procedures establish that nonradiation worker medical staff and caregivers should not receive an effective dose of greater than $5 \mathrm{mSv}$ for each treatment and that members of the general public should not receive an effective dose of greater than $1 \mathrm{mSv}$ when exposed to a patient after treatment (3).

At present, the effective dose to a caregiver is calculated by considering the ${ }^{131} \mathrm{I}$ to be concentrated in a point source in a patient, without shielding. The effective dose to the caregiver and members of the public is also calculated from a point source near the patient. This approach does not take into consideration the attenuation and scattering of the radiation by the human body. Other studies have used the line-source approximation instead of the point-source model for estimating the dose to an individual exposed to a patient who has received radioactivity (4), and anthropomorphic mathematic phantoms with Monte Carlo transport techniques have been proposed for a more accurate dose calculation $(5,6)$. The present study proposes a more realistic method for calculating radiation transport between patients and exposed individuals: the Monte Carlo method and anthropomorphic voxel phantoms.

To evaluate the doses received by caregivers and the general public, 3 exposure situations were considered. In the first, the caregiver spends one night close to the patient while hospitalized; in the second, the patient is accompanied by the caregiver during the journey from hospital to home; and in the third, the caregiver accompanies the patient in his or her daily routine. The calculations were done with mean biokinetic parameters obtained experimentally $(7,8)$; with the Visual Monte Carlo code (9), which simulates radiation transport by use of the Monte Carlo method; and with the female adult voxel phantom (FAX) (10), which is based on CT images and represents more realistic anatomic characteristics. The female adult voxel phantom FAX was used as the patient (source) and the target in the simulations because thyroid cancer is more common in women than in men. 


\section{MATERIALS AND METHODS}

\section{Voxel Phantom FAX}

This phantom presents anatomic structures comparable to those described for the "reference woman" in ICRP Publication 89 (11). The phantom consists of 453 slices obtained from a CT scan, resulting in a voxel phantom of an adult woman with a height of $1.63 \mathrm{~m}$ and a weight of $59.76 \mathrm{~kg}$. FAX includes 22 segmented organs and tissues and a total of 1,272,504 voxels of sides measuring $0.36 \mathrm{~cm} \times 0.36 \mathrm{~cm} \times 0.36 \mathrm{~cm}$.

\section{Visual Monte Carlo Code}

Various codes that simulate photon transport through nonhomogeneous structures have been written; among these codes are GEANT4 (12), MCNP (13), and FLUKA (14). The Visual Monte Carlo program was chosen for this study because it is written in the programming language Visual Basic version 6 and has visualization resources through its graphic interface. This software has already been applied to areas of radiation protection, including the calibration of in vivo measurement systems, calculations of doses from external sources of radiation, and calculations of specific effective energies (15).

\section{Calculation of Cumulated Activity}

Mean biokinetic parameters that describe the processes of uptake, retention, and clearance of ${ }^{131} \mathrm{I}$ were obtained experimentally. Among these were coefficients of the biokinetic equations that describe the behavior of ${ }^{131} \mathrm{I}$ in a patient's body. These coefficients were obtained from measurements of ${ }^{131} \mathrm{I}$ activities in thyroid remnants in various patients by the SPECT technique $(7,8)$. Activities calculated for each patient were plotted as a function of time, and the uptake and elimination phases were fitted with nonlinear regression to a 2-component exponential function.

The activity of ${ }^{131} \mathrm{I}$ in the thyroid and the time that it stays in this region depend on the properties and biologic characteristics of the radiopharmaceutical and of the individual's metabolism as well as on the physical half-life of the radionuclide. The total number of all nuclear transformations in this organ over a given time interval is defined here as $\tilde{A \text { : }}$

$$
\tilde{A}=\int_{t_{1}}^{t_{2}} A(t) d t
$$

In Equation 1, $A(t)$ is the activity in the thyroid as a function of time. The cumulated activity in any particular source organ is calculated by integrating the instantaneous activity over time. $A(t)$ can be described as the subtraction of 2 exponential terms:

$$
A(t)=a_{0} \cdot\left(e^{-a_{1} \cdot t}-e^{-a_{2} \cdot t}\right) .
$$

In Equation 2, $t$ is the time since the ingestion of ${ }^{131} \mathrm{I}, a_{0}$ is the initial maximum activity in the thyroid, and $a_{1}$ and $a_{2}$ are obtained experimentally. $a_{0}$ is calculated as follows:

$$
a_{0}=\frac{f \cdot A_{0}}{C}
$$

In Equation 3, $f$ is the maximum fraction captured by residues of the thyroid, $A_{0}$ is the initial activity administered to the patient, and constant $C$ is calculated as follows:

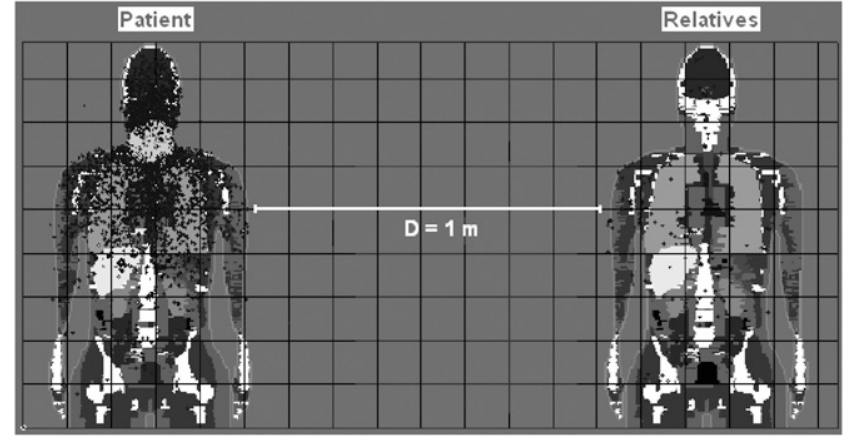

FIGURE 1. Simulation of sleeping in hospital. $D=$ distance.

$$
C=\left\{\frac{a_{2}-\left[\frac{a_{1}}{a_{1}}\right]}{\left[a_{2}-a_{1}\right)}-{\frac{a_{2}}{a_{1}}}^{\left[\frac{a_{2}}{\left[a_{2}-a_{1}\right)}\right]}\right\} .
$$

Substituting Equation 2 into Equation 1 yields:

$$
\tilde{A}=f \cdot A_{0} \cdot \int_{t_{1}}^{t_{2}}\left(e^{-a_{1} \cdot t}-e^{-a_{2} \cdot t}\right) d t .
$$

In this work, $a_{1}$ and $a_{2}$ values of 0.0129 and $0.577 \mathrm{~h}^{-1}$ were used; these values were experimentally derived from patients who had undergone a total thyroidectomy and had right and left thyroid residues with a total mass of $3 \mathrm{~g}$. The average percentage uptake in the remaining thyroid tissue was $3.8 \%(f)$ of ${ }^{131} \mathrm{I}$. A total activity intake of $11.1 \mathrm{GBq}(300 \mathrm{mCi})\left(A_{0}\right)$ of ${ }^{131} \mathrm{I}$ via ingestion was assumed; this value represented the most conservative dose. The calculations were made on the basis of the assumptions that all of the ${ }^{131} \mathrm{I}$ was concentrated in the thyroid remnants and that the rest of the ${ }^{131}$ I was quickly eliminated through the urine. These assumptions were based on the biokinetics of iodine in humans; that is, after $48 \mathrm{~h}$, all of the iodine present in the body has been taken up by the remaining thyroid tissue (1).

\section{Irradiation Geometries}

Three irradiation geometries representing conservative situations that a patient and a caregiver would be likely to experience during and after hospitalization were considered. The first exposure geometry simulated a situation in which the caregiver stayed in the patient's room in the hospital overnight. Before sleeping, the patient ingested ${ }^{131} \mathrm{I}$ at 07:00 $\mathrm{AM}$ and then began sleeping at 21:00 PM. This time interval represented $14 \mathrm{~h}$ of biologic and physical elimination of ${ }^{131}$ I from thyroid residues. From 21:00 PM
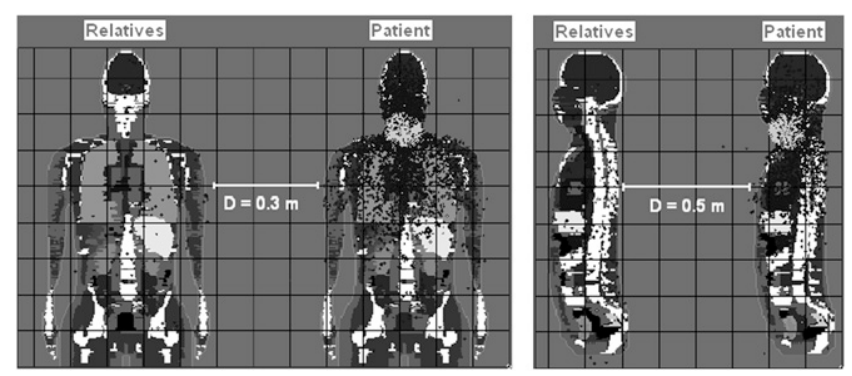

FIGURE 2. Simulation of patient's return home in car. D = distance. 
TABLE 1

Simulation of Travel to Home with Patient Beside Driver or Patient Behind Driver

\begin{tabular}{lcccc}
\hline Simulation & $\begin{array}{c}\text { Travel } \\
\text { time }(\mathrm{h})\end{array}$ & $\begin{array}{c}\text { Cumulated } \\
\text { activity }(\mathrm{Bq} \cdot \mathrm{s})\end{array}$ & $\begin{array}{c}\text { Patient-driver } \\
\text { geometry }\end{array}$ & $\begin{array}{c}\text { Distance } \\
(\mathrm{m})\end{array}$ \\
\hline 1 & 1 & $9.08 \times 10^{11}$ & Beside & 0.3 \\
2 & 3 & $2.70 \times 10^{12}$ & Beside & \\
3 & 5 & $4.42 \times 10^{12}$ & Beside & \\
4 & 1 & $9.08 \times 10^{11}$ & Behind & 0.5 \\
5 & 3 & $2.70 \times 10^{12}$ & Behind & \\
6 & 5 & $4.42 \times 10^{12}$ & Behind & \\
& & & & \\
& & & &
\end{tabular}

to $05: 00 \mathrm{AM}$, the patient and the caregiver slept in the same room and were assumed to be stationary during this 8-h sleeping period; this is the period that was simulated. The value of the cumulated activity in the thyroid residues in this case was $1.07 \times 10^{13} \mathrm{~Bq} \cdot \mathrm{s}$. The exposure geometry was assumed to be left lateral-right lateral for the 2 voxel phantoms. The patient phantom (source) and the caregiver phantom (target) were assumed to be side by side at a distance of $1.0 \mathrm{~m}$ from inside arm to inside arm (Fig. 1).

In the second exposure geometry, which simulated a return home, the patient returned home in the company of a caregiver or the general public, such as a taxi driver. In this situation, 2 scenarios were considered: the patient beside the caregiver or taxi driver at a distance of $0.3 \mathrm{~m}$ and the patient behind the caregiver or taxi driver at a distance of $0.5 \mathrm{~m}$ (Fig. 2). The exposure time for this simulation was the time required to travel from the hospital to the home. It was assumed that the patient was discharged from the hospital after $2 \mathrm{~d}$ of treatment. Cumulated activities were calculated for various travel times (Table 1).

The third exposure geometry simulated a situation in which the patient was in close contact (a distance of $0.3 \mathrm{~m}$ ) with the caregiver for $16 \mathrm{~h} / \mathrm{d}$ on days $2-7$ after the intake of ${ }^{131} \mathrm{I}$. A left lateral-right lateral exposure geometry was assumed for the 2 voxel phantoms. After current procedures, the patient is normally instructed to resume "normal contact" only $7 \mathrm{~d}$ after intake. Cumulated activities (number of nuclear transformations) were calculated for various days (Table 2).

For all of the exposure geometries, $10^{8}$ photon histories were used for the Visual Monte Carlo code runs to achieve an error in organ dose assessment of less than $5 \%$.

\section{RESULTS}

All effective dose calculations were made with the tissue weighting factors given in ICRP Publication 103 (16).

TABLE 2

Simulation of Close Contact of Patient and Caregiver (Side by Side at Distance of $0.3 \mathrm{~m}$ ) for 16 Hours

\begin{tabular}{lc}
\hline $\begin{array}{c}\text { Time between } \\
\text { intake and contact }(\mathrm{d})\end{array}$ & $\begin{array}{c}\text { Cumulated } \\
\text { activity (Bq.s) }\end{array}$ \\
\hline 2 & $1.32 \times 10^{13}$ \\
3 & $9.69 \times 10^{12}$ \\
4 & $7.12 \times 10^{12}$ \\
5 & $5.22 \times 10^{12}$ \\
6 & $3.84 \times 10^{12}$ \\
7 & $2.81 \times 10^{12}$ \\
\hline
\end{tabular}

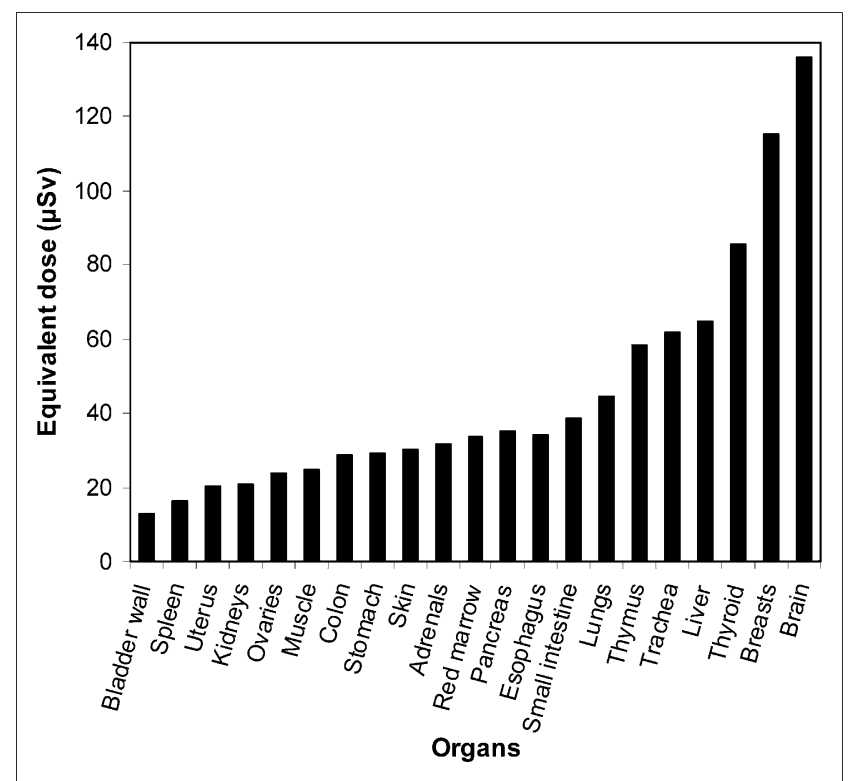

FIGURE 3. Equivalent organ doses in target phantom for $8 \mathrm{~h}$ of sleep at distance of $1.0 \mathrm{~m}$.

Calculated equivalent organ doses to the caregiver during the overnight stay in the hospital are shown in Figure 3. An effective dose of $0.05 \mathrm{mSv}$ was calculated for the caregiver.

Table 3 shows the calculated effective doses for an individual accompanying a patient immediately after discharge from the hospital. The highest dose was observed for the 5-h journey with the patient behind the driver at a distance of $0.5 \mathrm{~m}$.

Table 4 shows the calculated effective doses for a caregiver in close contact with a patient.

\section{DISCUSSION}

The present study was the first step in elaborating an alternative method for estimating doses from patients receiving radioiodine therapy by use of the Monte Carlo method and anthropomorphic voxel phantoms. One limitation of our study was the use of only the thyroid and not the whole body as the source of radioactivity. This choice was made because only experimental data (biokinetic parameters) for thyroid uptake from a specific group of patients were available to us. In the future, we intend to develop

TABLE 3

Calculated Effective Doses for Travel from Hospital to Home with Patient Beside or Behind Driver

\begin{tabular}{llcc}
\hline Distance $(\mathrm{m})$ & $\begin{array}{c}\text { Patient-driver } \\
\text { geometry }\end{array}$ & $\begin{array}{c}\text { Travel } \\
\text { time }(\mathrm{h})\end{array}$ & $\begin{array}{c}\text { Effective } \\
\text { dose }(\mu \mathrm{Sv})\end{array}$ \\
\hline 0.3 & Beside & 1 & 11.6 \\
& Beside & 3 & 34.2 \\
& Beside & 5 & 56.3 \\
0.5 & Behind & 1 & 18 \\
& Behind & 3 & 53 \\
& Behind & 5 & 87.4 \\
\hline
\end{tabular}


TABLE 4

Calculated Effective Doses for 16 Hours of Daily Close Contact of Patient and Caregiver as Function of Day After Intake

\begin{tabular}{lc}
\hline Day after intake & Effective dose $(\mu \mathrm{Sv})$ \\
\hline 2 & 170.2 \\
3 & 125 \\
4 & 91.4 \\
5 & 67.3 \\
6 & 49.3 \\
7 & 36.2 \\
Total & 539.3 \\
\hline
\end{tabular}

new irradiation geometries with more experimental data (from the thyroid and the rest of the body), other therapeutic radiopharmaceuticals, and combinations of adult male and female phantoms.

\section{CONCLUSION}

The results of this work show that the calculated effectives doses were less than $0.85 \mathrm{mSv}$ when doses attributable to all of the simulated exposure geometries were considered. This finding implies that even for the overnight stay of the caregiver, the presence of the caregiver on a 5-h trip home, and the close contact of the caregiver with the patient at home for $16 \mathrm{~h} / \mathrm{d}$ on days $2-7$, the total effective doses were considerably lower than the 5-mSv limit established in U.S. Nuclear Regulatory Commission Regulatory Guide 8.39 and lower than the $1-\mathrm{mSv}$ limit above which release instructions are required (3). This finding suggests that for these patients receiving radioiodine therapy, radiation protection procedures after hospital discharge are unnecessary. However, other radiation protection measures, such as control of urine, the primary via of excretion of iodine, must be implemented to minimize the spread of contamination when such patients are released. The relaxing of conservative radiation protection procedures will result in psychologic benefits for patients and their families.

\section{REFERENCES}

1. International Commission on Radiological Protection. Release of Patients After Therapy with Unsealed Radionuclides. Oxford, U.K.: Pergamon Press; 2004. ICRP Publication 94.

2. Willegaignon J, Malvestiti LF, Guimarães MIC, et al. ${ }^{131}$ I effective half-life $\left(T_{\text {eff }}\right)$ for patients with thyroid cancer. Health Phys. 2006;91:119-122.

3. U.S. Nuclear Regulatory Commission. Release of Patients Administered Radioactive Materials. Washington, DC: U.S. Nuclear Regulatory Commission; 1997:2. Regulatory Guide 8.39 .

4. Siegel JA, Marcus CS, Sparks RB. Calculating the absorbed dose from radioactive patients: the line-source versus point-source model. J Nucl Med. 2002;43:12411244

5. Sparks RB, Siegel JA, Wahl RL. The need for better methods to determine release criteria for patients administered radioactive material. Health Phys. 1998;75:385388.

6. Sherbini SS, Decicco JE. The use of radiation surveys to estimate the radiation effective dose to visitors of hospitalized patients: a theoretical study. Health Phys. 2005;89:216-223.

7. Farias F, Stabin M, Khoury HJ. Optimization of ablative dose for thyroid cancer. Alasbimn Journal. 2007;9:36.

8. Khoury HJ, Farias F, Stabin M. Volume and active concentration estimation in phantom of thyroid tissue remnants using SPECT. Radioprotecção. 2004;4/5: 44-53.

9. Hunt JG, Da Silva FCA, Dos Santos DS, et al. Visual Monte Carlo and its application to internal and external dosimetry. In: Kling A, Barao F, Nakagawa M, Tavora L, Vaz P, eds. Advanced Monte Carlo for Radiation Physics, Particle Transport Simulation and Applications. Proceedings of the Monte Carlo 2000 Conference. Berlin, Germany: Springer-Verlag; 2000:345-350.

10. Kramer R, Khoury HJ, Vieira JW, et al. All about FAX: a female adult voxel phantom for Monte Carlo calculations in radiation protection dosimetry. Phys Med Biol. 2004;49:5203-5216.

11. International Commission on Radiological Protection. Basic Anatomical and Physiological Data for Use in Radiological Protection. Oxford, U.K.: Pergamon Press; 2003. ICRP Publication 89.

12. Agostinelli S, Allison J, Amako K, et al. GEANT4: a simulation toolkit. Nucl Instrum Methods Phys Res. 2003;506:250-303.

13. Briesmeister JF. MCNP: a general Monte Carlo code for neutron and photon transport. Los Alamos, NM: Los Alamos National Laboratory; 1986. Publication LA-7396.

14. Fasso A, Ferrari A, Ranft J, Sala PR. FLUKA: status and prospective for hadronic applications. In: Kling A, Barao F, Nakagawa M, Tavora L, Vaz P, eds. Advanced Monte Carlo for Radiation Physics, Particle Transport Simulation and Applications. Proceedings of the Monte Carlo 2000 Conference. Berlin, Germany: Springer-Verlag; 2000:955-960.

15. Hunt JG, Da Silva FCA, Mauricio CLP, et al. The validation of organ dose calculations using voxel phantoms and Monte Carlo methods applied to point and water immersion sources. Radiat Prot Dosimetry. 2004;108:85-89.

16. International Commission on Radiological Protection. Recommendations of the International Commission on Radiological Protection. Oxford, U.K.: Pergamon Press; 2007. ICRP Publication 103. 